\title{
Stability Analysis of Xujiazhuang Dam during Construction Period
}

\author{
Xiaocheng Su \\ School of Resources and Environment, University of Jinan, Jinan, China,250022 \\ suxiaocheng@tju.edu.cn
}

\begin{abstract}
Through the stability of the construction process of Xujiazhuang dam is analyzed, the main problems in the dam construction process can be clarified. In this paper, the dam model is established by using the finite element software P LAX IS to simulate the settlement displacement and stress variation of the dam construction process. The results show that the maximum sedimentation displacement is $3.50 \mathrm{~cm}$ and the maximum horizontal displacement is $1.56 \mathrm{~cm}$ after the dam impervious area is completed. After the completion of the dam, the maximum settlement displacement of the dam is $12.96 \mathrm{~cm}$, accounting for $0.54 \%$ of the dam height, in line with the specifications of the compaction earth dam design requirements shall not exceed the dam height of $1 \%$ of the provisions. During the whole settlement of the dam, the settlement process of the impermeable body and other filling material areas is uniform. The results of the alone for the successful completion of dam construction to provide an important reference.
\end{abstract}

Keywords: stability, Xujiazhuang dam, construction

\section{INTRODUCTION}

Dam is a valuable asset left to mankind. With the development of social economy and the continuous progress of human society, people fully tap the benefits of the dam can bring people, dam in addition to the most basic role in flood control and the role of regulation of runoff to protect the safety of national life and property, but also for The surrounding area provides residential water, agricultural water and industrial water. It is part of the canal system, people can use the dam to meet people's electricity demand.

In order to meet the needs of China's national economic development, the number of dams in our country is huge, and the dam is destroyed and the disasters are devastating and unimaginable. At the same time, the normal social and economic benefits of these dams are restricted. According to statistics, China in more than 50 years a total of more than 3,800 dam dam, dam dam to the people downstream of the reservoir has brought serious loss of life and property. Therefore, the stability of the dam construction period analysis is necessary and urgent. 


\section{FINITE ELEMENT ANALYSIS}

Finite element analysis is a numerical method that has been widely used. The idea of finite element is to decompose a complex assemblage into several small units, and then analyze the small units one by one by force analysis and then make a whole analysis of the final analysis of the calculation of a zero, the complex is simple A calculation method.

Finite element analysis can be used to analyze some of the more complex problems that can not be solved by traditional algebraic methods. Through the finite element method to analyze the problem can be more accurate results. At the beginning of the plane is often used to solve the structural problems, as of now also extended to solve the three-dimensional and plate-related issues.

\section{PROJECT OVERVIEW}

Xujiazhuang dam is located in the Yixi County in the northwest of the township, from the north of $\mathrm{Xu}$ village about one thousand meters, is the Wei River, the upper reaches of the river. Started construction in November 1976, completed in April 1977 the main building of the dam, and gradually completed the spillway and the release of water and other dam supporting the construction of the project.

Xujiazhuang reservoir dam was roughly east-west direction, a total length of 434 meters, crest width of 3.6 to 4.2 meters. The main structure is composed of clay core sand shell dam. The core wall is made into the soil bedrock. The crest elevation is 292.90 meters, the maximum dam height is 24.2 meters, and the width of the core wall is about 2 meters.

\section{STABILITY ANALYSIS}

In order to analyze the stability of Xujiazhuang dam, the following figure is taken to calculate the cross-sectional view, and the finite element model is established. According to the upstream dike area, the impervious area, any material area, the filling is calculated and the maximum settlement displacement And stress changes.

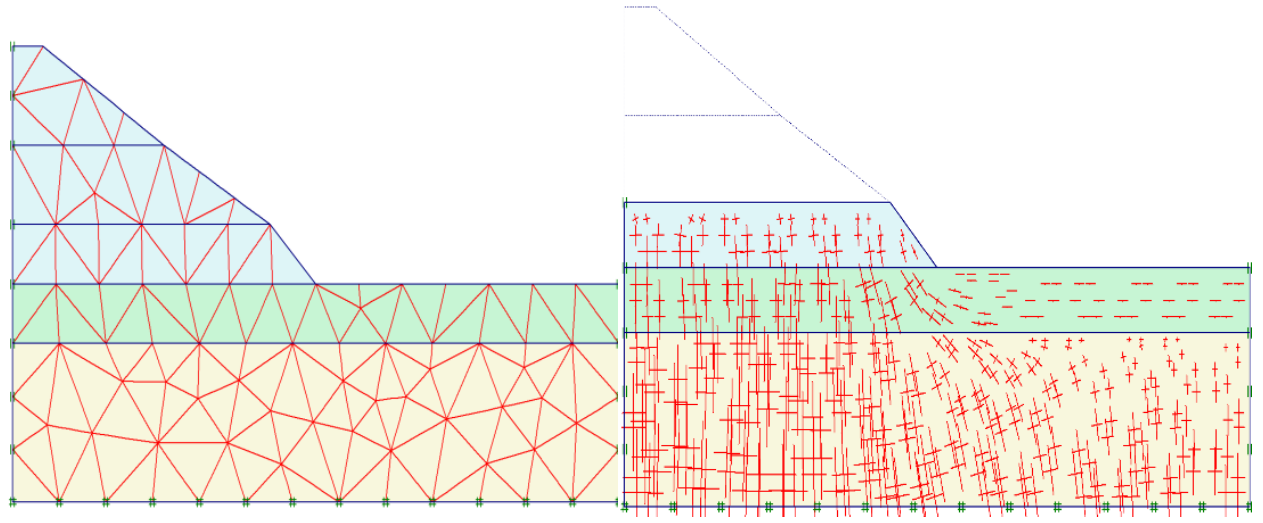

Fig. 4.1 mesh of dam deformation

Fig. 4.2Effective stress of slope 
Subgrade construction consists of two phases, each requiring 5 days. After the completion of the first construction phase, a consolidation period will be performed in order to allow the ultra-static water pressure to dissipate. After the second construction phase is completed, another consolidation period will be performed, where the final settlement of the soil can be determined. Therefore, a total of four calculation processes must be defined.

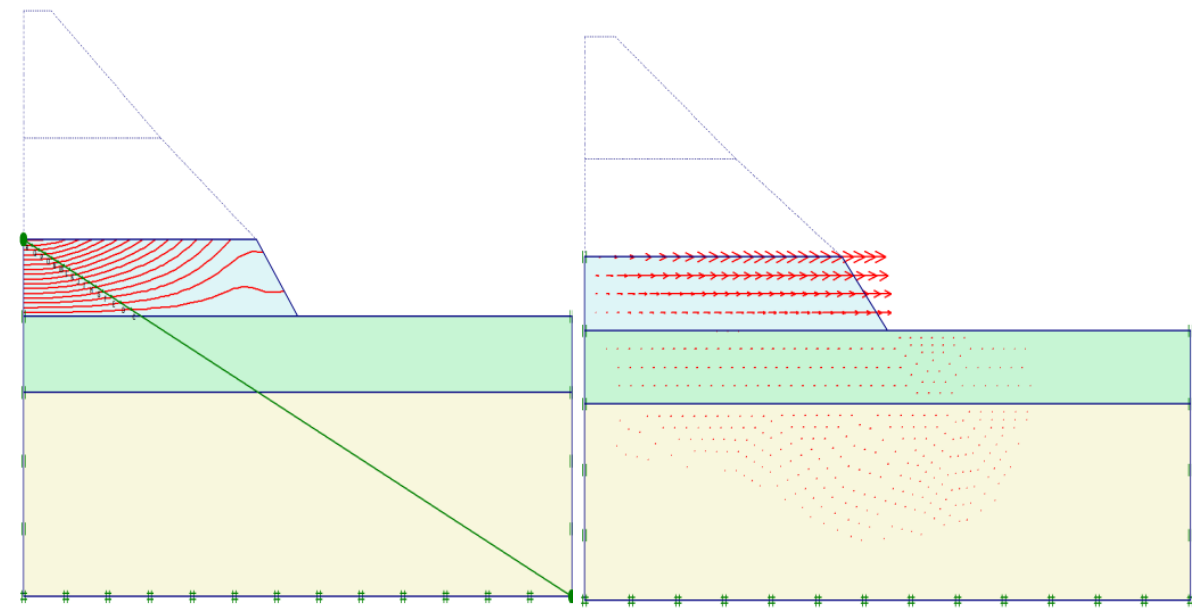

Figure 4.3 active pore pressure figure Fig. 4.4 displacement deformation

Roadbed construction includes two stages, each need 5 days. After completion of the first construction phase, a period of consolidation will be performed in order to allow excess hydrostatic pressure to dissipate. Second after the completion of the construction phase, another consolidation period will be performed, and the final settlement of the soil can be determined. Therefore, a total of 4 calculation procedures must be defined.

According to the analysis of the results, we can get the following table:

Table .1. maximum displacement table

\begin{tabular}{lccc}
\hline Partition construction & $\begin{array}{l}\text { Upstream displacement } \\
(\mathbf{c m})\end{array}$ & $\begin{array}{c}\text { Downstream displacement } \\
(\mathbf{c m})\end{array}$ & $\begin{array}{c}\text { Vertical settlement } \\
(\mathbf{c m})\end{array}$ \\
\hline The upstream area of dike & 0.29 & 0.60 & 1.60 \\
Impervious area & 1.56 & 2.86 & 3.50 \\
Arbitrary material area & 6.12 & 3.01 & 7.86 \\
\hline
\end{tabular}

CONCLUSION

In this paper, through the establishment of homogeneous dam slope model, using the finite element software modeling and analysis, respectively, from the two aspects of the change of the settlement displacement and the relationship between the stress of the following conclusions:

When the dam is completed, the maximum settlement displacement of the dam is $12.96 \mathrm{~cm}$, accounting for about $0.54 \%$ of the dam height, which is in accordance with the requirements of the code for design of 
roller compacted earth rock dam, which should not exceed the dam height of $1 \%$. During the process of settlement, the settlement process of the impervious body and any material area is uniform.

The stress changes mainly occur in any material area, and the stress and deformation of the impervious body and the upper part of any material are easy to occur.

\section{ACKNOWLEDGMENTS}

The study is financially supported by the science and technology planning project of colleges and universities in Shandong Province (J14LH01), University of Jinan Found and the National Natural Science Fund (XKY1135).

\section{REFERENCES}

[1] Chen Kaiwu, Hui Shi Bing, song Guang Pu. The reinforcement of [J]. Sichuan water conservancy, 2005 (3): 30-32.

[2] Zhu Bofang. Principle and application of finite element method [M]. China Water Conservancy and Hydropower Press, 1983:42-43.

[3] Mo Chan. The study methods of slope stability [J]. Chinese water, 2007,7 (2): 6-8.

[4] Xiao Zhengmin. Stability analysis of [J]. landslide in Yunnan Province Coal Mine Design Institute by Morgan Stein - price method, 1989,6 (1): 16-20.

[5]Dan Neumayer, Madhukar Chatiri, Matthias Hoermann. Droptest simulation of a cooker including $f$ oam packaging an dprestressed plastic foil wrapping [A].The 9th international LS -DYNA user conf erence[C].Dearborn:LS TC,2006:34-40.

[6] Shigeki Kojima. Development of aluminum honeycomb model using shell element s[A].The 9th int ernational LS-DYNA user conference[C].Dearborn:LSTC,2006:1-10.

[7] Ling Huang, Hiroshi Hikosaka, Keizo Komine. Simulation of accordion effect in corrugated steel web with concrete of langes[J].Computers and Structures, 2004(82):2061-2069.

[8] Duncan J M. State of the art: limit equilibrium and finiteelement analysis of slopes [J].Journal of Geotechnical Engineering,1996,122(7):577 596[30] Zhang X.Three-dimensinoal stability analysis of concaveslope in plan view [J] . ASCE Journal of GeotechniqueEngineering,1998,114:658 671. 